\title{
Anterior Cingulate and Subgenual Prefrontal Blood Flow Changes Following Tryptophan Depletion in Healthy Males
}

\author{
Peter S Talbot*,' and Stephen J Cooper' \\ 'Division of Psychiatry \& Neuroscience, Queen's University Belfast, Northern Ireland, UK
}

\begin{abstract}
In healthy humans, there is an apparent dissociation between cognitive and affective consequences of reduced brain serotonin (5-HT), as rapid tryptophan depletion (RTD) causes alterations in a consistent constellation of cognitive processes in the general absence of mood deterioration. This study aimed to investigate possible neural mechanisms underlying this relative dissociation by measuring the effects of reduced 5-HT on regional cerebral blood flow (rCBF). A total of 16 healthy, euthymic male subjects (mean age $39 \pm 9$ years) without a personal or family history of affective disorder had mood ratings and single photon emission computed tomography scans with the rCBF tracer ${ }^{99 \mathrm{~m}} \mathrm{Tc}$-HMPAO under reduced 5-HT (RTD) and control conditions. Across individuals, modest positive and negative changes in subjective happiness associated with RTD were significantly correlated with change of rCBF in a cluster comprising subgenual (affective) anterior cingulate cortex (ACC) and associated regions (Brodmann's area (BA) 25, posterior BAII and 47, caudate nucleus and ventral striatum; SPM99 $p<0.05$, corrected). The covariation was such that increasing sadness was associated with increased rCBF and vice versa. Independent of mood change, RTD was associated with reduced rCBF in the dorsal (cognitive) ACC (BA32; SPM99 $p<0.05$, corrected). The subgenual prefrontal cortex and dorsal ACC are important components of the ventral and dorsal neural systems that regulate and integrate affective and cognitive functions. The results therefore suggest that the dissociation between affective and cognitive consequences of RTD may possibly be attributable to differential effects of reduced 5-HT on these neural systems.

Neuropsychopharmacology (2006) 31, 1757-1767. doi: I0.1 038/s.npp. I 30 I022; published online II January 2006
\end{abstract}

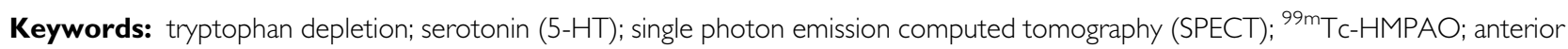
cingulate; subgenual prefrontal cortex

\section{INTRODUCTION}

Rapid tryptophan depletion (RTD) is a research technique for transiently reducing brain serotonin (5-hydroxytryptamine; 5-HT) by the ingestion of an excess of large neutral amino acids in the absence of tryptophan (Trp), the precursor of 5-HT. In healthy humans, RTD alters a number of cognitive processes (Riedel, 2004). Most consistently affected across studies are the encoding or consolidation of new information into long-term memory (Harrison et al, 2004; Klaassen et al, 2002, 1999; McAllisterWilliams et al, 2002; Park et al, 1994; Riedel et al, 1999; Rubinsztein et al, 2001; Schmitt et al, 2000; Sobczak et al, 2002), attentional tasks requiring a subject to respond to a specific stimulus dimension while suppressing interference from a competing dimension (eg Stroop Color Word

\footnotetext{
*Correspondence: Dr PS Talbot, Wolfson Molecular Imaging Center, The University of Manchester, 27 Palatine Road, Withington, Manchester M20 3LJ, UK, Tel: + 44 I6I 275 00I5, Fax: + 44 I6I 275 0003, E-mail: peter.Talbot@Manchester.ac.uk

Received 9 May 2005; revised 28 September 2005; accepted 29 November 2005

Online publication: 6 December 2005 at http://www.acnp.org/citations/ Npp I 20605050307/default.pdf
}

interference task) (Coull et al, 1995; Rowley et al, 1997; Schmitt et al, 2000), decision making (Rogers et al, 1999b, 2003), and reversal learning (Park et al, 1994; Rogers et al, 1999a).

In addition, RTD may precipitate transient mood deterioration in vulnerable populations, particularly patients with major depressive disorder (MDD) in early remission maintained on serotonergic antidepressant medications, and (less consistently) unmedicated subjects with a personal or family history of depression (Booij et al, 2003; Moore et al, 2000). Neuroimaging studies in untreated patients with MDD have repeatedly identified abnormalities of regional cerebral blood flow (rCBF) and glucose metabolism (rCMRglc), most consistently in ventral subdivisions of prefrontal and anterior cingulate (ACC) cortices, but also in other limbic and subcortical regions including hippocampus, amygdala, posterior cingulate, striatum, and thalamus (Drevets, 2000a, b; Liotti and Mayberg, 2001; Seminowicz et al, 2004). Although there is a growing consensus that this network of brain areas is implicated in depression, there is variability in the exact regions reported and in the direction of $\mathrm{rCBF}$ and rCMRglc changes. This may reflect multiple depression phenotypes (with differential response to treatments), differences 
related to underlying disease processes (trait effects), differing symptom severity (state effects), or differences in the tasks performed by subjects during scan acquisition. In MDD, RTD induces significant changes in $\mathrm{rCBF}$ and rCMRglc in this depression-related neural network, both associated with RTD-induced mood deterioration (Bremner et al, 1997; Morris et al, 1999; Smith et al, 1999) and apparently independent of mood change (Neumeister $e t a l$, 2004). Although there are relative differences in regional and directional findings across these studies, possibly related to differences in methodology, medication status, and severity of RTD-induced mood deterioration, they support the hypothesis that (at least in a significant proportion of patients) the dysfunction in the depressionrelated neural network is 5-HT-related and can be unmasked by transient 5-HT reduction even in the absence of depressive symptoms.

In contrast to patients with MDD, healthy subjects, even on SSRI medication (Barr et al, 1997), do not generally experience RTD-induced mood deterioration. Moreover, RTD-induced cognitive changes in groups of healthy subjects are generally measured in the absence of a significant mean alteration of mood. There thus appears to be a relative dissociation between cognitive and affective consequences of the reduced brain 5-HT associated with RTD in healthy subjects. This dissociation may not hold true in MDD. For example, many studies have demonstrated wide-ranging neuropsychological deficits in depressed patients, and neuroimaging findings in MDD have shown that increasing severity of depression following RTD is associated with a significant attenuation of cognitioninduced activation in the dorsal ACC (Smith et al, 1999). However, in comparison to patients with MDD, relatively little is known about the neural correlates of 5-HT reduction by RTD in healthy subjects. Neumeister et al (2004) found only small, nonsignificant, reductions in rCMRglc in posterior cingulate cortex and medial thalamus in a control group of healthy men and women who developed no significant mean change in mood following RTD. However, the amino-acid load was relatively small compared to most typical RTD studies, and positron emission tomography (PET) with $\left[{ }^{18} \mathrm{~F}\right]$ fluorodeoxyglucose (FDG) has relatively poor temporal resolution for correlating transient changes in mood and brain activity due to the prolonged uptake time of the tracer $(\sim 45 \mathrm{~min})$. In a small single photon emission computed tomography (SPECT) study, Pergadia et al (2004) found that heavy smokers, both with and without a history of depression, responded to RTD with mood deterioration and an associated reduction in $\mathrm{rCBF}$ in inferior frontal cortex. As a similar pattern was found in patients with MDD (Smith et al, 1999), the authors concluded that heavy smoking may convey a biological vulnerability to depression. The mood and brain responses to RTD in these subjects may therefore not be considered comparable to those of other healthy subjects.

The primary objective of the current study was to investigate neural correlates of a typical RTD paradigm, in an exploratory manner, in a group of healthy subjects without a personal or family history of affective disorder. Brain activity was measured using the SPECT blood flow tracer technetium- $99 \mathrm{~m}$ hexamethyl propyleneamine oxime $\left({ }^{99 \mathrm{~m}} \mathrm{Tc}-\mathrm{HMPAO}\right.$; exametazime; Ceretec). The a priori hypothesis was that RTD-associated $\mathrm{rCBF}$ changes would be found in neural circuits consistent with the documented effects of RTD on cognitive functions. The second aim was to measure activity changes associated with, and independent of, RTD-induced mood change, in order to investigate possible explanations for the apparent dissociation between cognitive and affective consequences of RTD in healthy humans.

\section{MATERIALS AND METHODS}

\section{Subjects}

The study was approved by the Research Ethics Committee of the Faculty of Medicine, Queen's University Belfast, and the Administration of Radioactive Substances Advisory Committee (ARSAC, UK). A total of 16 paid, healthy male volunteers (mean \pm SD age: $39.4 \pm 8.6$ years, range $23-50$ years; 14 right-handed, 2 left-handed) were recruited through advertisements placed around the university. Only male subjects were studied in an attempt to avoid possible confounding effects of gender differences within the group, and because of difficulties in using neuroimaging techniques involving radioactivity in female subjects of childbearing age in the UK. Only one subject was a cigarette smoker (10-20 cigarettes/day). In order to prevent possible confounding effects of nicotine withdrawal, he was permitted to smoke one or two cigarettes during each study day, but had to abstain for at least $1 \mathrm{~h}$ before the start of SPECT scanning. One subject had been taking a low dose of a prescribed analgesic medication for several years (acetaminophen $1000 \mathrm{mg}$ plus dihydrocodeine $60 \mathrm{mg}$, at night) for back pain. He was requested not to omit any doses during the study. No other subjects were receiving regular medication. All subjects received detailed verbal and written descriptions of the purpose and nature of the research, and had the opportunity to ask questions, following which they gave written consent.

\section{Screening}

Before enrolment, participants underwent a semistructured interview with a psychiatrist (PST) and were subject to routine physical examination, hematological and biochemical screening, and urine toxicology screen. Exclusion criteria were: a personal history of affective disorder or schizophrenia, or a family history of either disorder in a first-degree relative; current evidence of depressed mood as indicated by a score $\geqslant 9$ on the Beck Depression Inventory (BDI) (Beck et al, 1961); evidence of organic brain pathology, including epilepsy, or a lifetime history of head injury resulting in loss of consciousness for longer than $5 \mathrm{~min}$; weekly alcohol intake exceeding 21 units (1 unit is equivalent to $8 \mathrm{~g}$ or $10 \mathrm{ml}$ of pure alcohol, ie approximately one-half pint of ordinary strength beer, one small glass of wine or one $25 \mathrm{ml}$ measure of a spirit); past history of drug (including cannabis) or alcohol misuse or dependence.

\section{RTD Procedure}

The RTD paradigm was applied in a double-blinded, within-subject, counterbalanced, crossover design over two 
separate days (6-14 days apart), with random assignment to the order of condition (RTD or control condition first). RTD was achieved through a Trp-free $(\mathrm{T}-)$ amino-acid mixture administered $5 \mathrm{~h}$ before SPECT scanning. The $\mathrm{T}-$ mixture (100 g) comprised 15 amino acids (L-alanine $5.5 \mathrm{~g}$, L-arginine $4.91 \mathrm{~g}, \mathrm{~L}$-cystine $2.71 \mathrm{~g}$, glycine $3.2 \mathrm{~g}$, L-histidine $3.2 \mathrm{~g}$, L-isoleucine $8.0 \mathrm{~g}$, L-leucine $13.5 \mathrm{~g}$, L-lysine $11.0 \mathrm{~g}$, L-methionine $2.99 \mathrm{~g}$, L-phenylalanine $5.7 \mathrm{~g}$, L-proline $12.2 \mathrm{~g}$, L-serine $6.9 \mathrm{~g}$, L-tyrosine $6.9 \mathrm{~g}$, L-valine $8.9 \mathrm{~g}$, L-threonine $6.9 \mathrm{~g}$ ) along with carbohydrate (maltodextrin) $8.1 \mathrm{~g}$, made up in $200 \mathrm{ml}$ of bottled water. A proprietary blackcurrant flavor was added to improve palatability. The control $(\mathrm{T}+)$ mixture consisted of the same amino acids plus L-Trp $2.3 \mathrm{~g}$ and a compensatory reduction in the maltodextrin content to $5.8 \mathrm{~g}$. The maltodextrin in the mixtures was added to make them up to $100 \mathrm{~g}$ and to give an equivalent nitrogen content to each mixture. Blood samples for analysis of plasma total Trp concentration were taken before drinking the amino-acid mixture and before SPECT scanning, and were measured by high-performance liquid chromatography with fluorescence detection.

\section{Clinical Ratings}

On each morning, before drinking the amino-acid mixture, subjects rated their subjective mood state using the BDI, Spielberger Self-Evaluation Questionnaire (State version) for anxiety (SEQ) (Spielberger et al, 1971), and a $100 \mathrm{~mm}$ visual analogue mood scale (VAMS) with 'Happy' at one end and 'Sad' at the other (Folstein and Luria, 1973). These ratings were repeated $5 \mathrm{~h}$ later at the time of the injection of the radiotracer for the SPECT scan.

\section{Image Acquisition and Processing}

For each scan, subjects received an intravenous injection of approximately $250 \mathrm{MBq}(6.75 \mathrm{mCi})$ of ${ }^{99 \mathrm{~m}} \mathrm{Tc}-\mathrm{HMPAO} 5 \mathrm{~h}$ after ingestion of the amino-acid mixture (ie the approximate time of maximal plasma Trp depletion) as part of a half-dose scanning procedure, that is, a full dose (500 MBq) was split between two scans to limit radiation exposure. The reliability of voxel-wise comparison of the images produced by $250 \mathrm{MBq}$ doses of ${ }^{99 \mathrm{~m}} \mathrm{Tc}-\mathrm{HMPAO}$ has been previously established (Ebmeier et al, 1991). The ${ }^{99 \mathrm{~m}} \mathrm{Tc}-\mathrm{HMPAO}$ was made up before each injection using generator eluate less than $2 \mathrm{~h}$ old, and was injected within 10 min of being made up. Quality control indicated that this produced ${ }^{99 \mathrm{~m}} \mathrm{Tc}$ HMPAO containing $>95 \%$ diffusible ('primary') complex.

With ${ }^{99 m}$ Tc-HMPAO SPECT, the image acquired by the gamma camera corresponds to the pattern of $\mathrm{rCBF}$ at the time of tracer injection, not the $\mathrm{rCBF}$ at the time of image acquisition. Therefore, in order to standardize the mental state during the period of tracer brain uptake ( $\sim 3 \mathrm{~min}$ ), subjects were seated in a quiet room in which the levels of lighting and ambient noise were controlled. An intravenous cannula was placed in the nondominant arm, at least $10 \mathrm{~min}$ before radiotracer injection. In all cases, the injection was performed in silence shortly after the subjects had started to fill in the BDI. Subjects were instructed beforehand to ignore the injection and continue to fill in the BDI, then move on to the SEQ and VAMS in that order. After the tracer injection, subjects completed the rating scales then sat in silence looking at a neutral-toned wall until 5 min from the time of injection had elapsed. They were then moved to the gamma camera. In this way, the SPECT images corresponded to the pattern of $\mathrm{rCBF}$ at a time when subjects were internally evaluating their subjective mood in a standardized manner.

SPECT imaging was performed with the Siemens E.CAM dual-headed gamma camera (Siemens Medical Engineering Group, Erlangen, Germany) fitted with low energy highresolution collimators. The system resolution was $8 \mathrm{~mm}$ full-width at half-maximum (FWHM) at a distance of $10 \mathrm{~cm}$. The auto contour facility was used, in 'step and shoot' mode, giving a noncircular orbit in which both collimators were as close to the subject's head as possible at all times. Each acquisition used a zoom factor of 1.78 (giving a postreconstruction voxel size of $2.694 \mathrm{~mm}^{3}$ ) and a matrix of $128 \times 128$, with 64 views at $40 \mathrm{~s}$ per view. Scan time was approximately $47 \mathrm{~min}$.

Images were reconstructed using proprietary Siemens ICON software, by filtered back-projection using a Butterworth filter (frequency cutoff 0.35 Nyquist, order 10). Attenuation was corrected using Chang's first-order method (coefficient $0.12 / \mathrm{cm}$ ). In order to maintain counts in these relatively low-dose SPECT studies, scatter correction was not performed. Transverse image files were exported in Interfile format into MEDx imaging software (Sensor Systems, Inc. Sterling VA). Individual images were re-sliced to generate the same number of slices per study, and saved in ANALYZE format (Mayo Clinic, Rochester).

\section{Image Analysis}

SPECT data were analyzed using Statistical Parametric Mapping (SPM99, Wellcome Department of Cognitive Neurology; University College London, UK) implemented in MATLAB (MathWorks, Natick, MA). For each subject, the second image was realigned to the first (using a sixparameter rigid body transformation with least-squares cost function) and both images were normalized to a standard SPECT template space based on the atlas of Talairach and Tournoux (1988). Spatially normalized images were then smoothed to approximately twice the FWHM system resolution (Van Laere et al, 2002) using an isotropic (18 mm FWHM) Gaussian filter to reduce the error variance associated with individual variability in gyral anatomy, to improve the signal-to-noise ratio, and to precondition the data to fit the Gaussian distribution more closely. Global flow differences were normalized voxel-by-voxel to a mean of $50 \mathrm{ml} / \mathrm{dl} / \mathrm{min}$ by proportional scaling, and the gray matter threshold was set at $80 \%$ of the maximum voxel value in the volume. The general methods employed by SPM are described in detail elsewhere (eg, see Ashburner and Friston, 1999; Ashburner et al, 1997; Frackowiak et al, 1997; Worsley et al, 1996).

\section{Statistics}

Mood scores. On both study days, the morning BDI, SEQ, and VAMS scores were subtracted from the afternoon scores, to give a $\Delta$ score for each rating scale. The $\Delta$ score on the control day was subtracted from the $\Delta$ score on the RTD day, to give a $\Delta \Delta$ score for each rating scale. Because 
the two study days were as identical as possible in all respects other than the composition of the amino-acid mixture, the $\Delta \Delta$ score was attributed to an effect of RTD. Nonspecific mood effects due to the study protocol and amino-acid drinks (eg hunger, mild nausea, anticipatory anxiety, etc) were considered to be controlled for by the study design. The significance of the $\Delta \Delta$ scores was assessed by Student's $t$-test (paired, two-tailed).

SPECT images. To study differences in rCBF, the SPM analysis to visualize regional changes on a voxel-wise basis between the RTD and control conditions used a repeated measures design with $\triangle$ VAMS scores as a covariate. Because of the exploratory nature of the study, the threshold for statistical significance was set at $p \leqslant 0.05$, corrected for multiple comparisons across the whole brain. To identify significant clusters, the SPM T-maps were thresholded at an uncorrected voxel height of $p=0.01(t=2.62)$, and clusters with corrected values of $p \leqslant 0.05$ are reported.

Contrasts were specified to perform two main analyses. First, to examine the relationship between changes in mood and $\mathrm{rCBF}$, difference images obtained by subtracting the SPECT images in the RTD condition from the SPECT images in the control condition were tested for a significant correlation with $\triangle$ VAMS scores. Second, to examine an effect of RTD on rCBF independent of mood change, difference images were compared with the change in $\mathrm{rCBF}$ associated with mood change treated as a nuisance covariate.

SPM99 coordinates were identified using the atlas of Talairach and Tournoux, following nonlinear transformation from Montréal Neurological Institute (MNI) space using the algorithm mni2tal provided by Matthew Brett (MRC Cognition and Brain Sciences Unit, UK; http://www. mrc-cbu.cam.ac.uk/Imaging/Common/mnispace.shtml). In addition, SPM T-maps were superimposed onto the highresolution 152-subject average $\mathrm{T}_{1}$-weighted MRI image supplied with SPM99, which is spatially normalized to the same stereotaxic space (MNI).

\section{RESULTS}

\section{Serum Trp Levels}

As expected, RTD lowered the mean plasma Trp concentration by $86.2 \%(13.2 \pm 2.5$ and $1.7 \pm 0.4 \mu \mathrm{g} / \mathrm{ml}$ before and after $\mathrm{T}-$ drink, respectively; $p<0.0001)$ and the control condition increased the mean plasma Trp concentration by $64.0 \%(11.6 \pm 2.4$ and $19.3 \pm 7.6 \mu \mathrm{g} / \mathrm{ml}$ before and after $\mathrm{T}+$ drink, respectively; $p<0.01$ ).

\section{Mood}

Mean scores on the morning of the first day confirm that, as a group, subjects were neither depressed (BDI: $1.1 \pm 1.3$, range 0-4) nor anxious (SEQ: 46.2 \pm 4.9 , range 40-59). There was no significant difference between morning scores on both days (BDI: $p=0.45$; SEQ: $p=0.42$ ), nor between $\Delta$ scores on both days for BDI (control: $0.4 \pm 1.5$, range -2 to 5; RTD: $0.0 \pm 1.4$, range -2 to 4 ; $p=0.22$ ) or SEQ (control: $-0.9 \pm 2.4$, range -6 to 4 ; RTD: $0.4 \pm 3.5$, range -8 to 8 ; $p=0.16$ ). For the 'Happy-Sad' VAMS, subjects experienced a range of modest subjective mood changes associated with the control drink ( $\triangle$ VAMS: $5.7 \pm 8.1 \mathrm{~mm}$, range -3 to $+28 \mathrm{~mm}$ ) and RTD drink ( $\triangle$ VAMS: $0.5 \pm 6.1 \mathrm{~mm}$, range -11 to $+12 \mathrm{~mm}$ ), where positive $\triangle \mathrm{VAMS}$ values indicate a change towards the 'Sad' end of the line. The difference in $\triangle$ VAMS scores between conditions indicated that RTD was associated with a mean change of $5.2 \mathrm{~mm}$ towards the 'Happy' end of the scale ( $\Delta \Delta$ VAMS: $-5.2 \pm 9.4 \mathrm{~mm}$, range -29 to + $8 \mathrm{~mm}$ ). This mean difference across conditions just reached significance $(p=0.04)$. Individual $\triangle$ VAMS scores were used as covariates in the SPM analysis.

\section{Regional Cerebral Blood Flow}

There was no significant difference in injected dose of ${ }^{99 \mathrm{~m}} \mathrm{Tc}$-HMPAO between conditions (RTD: $266 \pm 13 \mathrm{MBq}$; control: $265 \pm 11 \mathrm{MBq} ; p=0.80$, paired $t$-test). In the voxellevel analysis, no voxels survived correction for multiple comparisons across the whole brain volume in any of the contrasts. On cluster-level analysis (Table 1), the change in subjective mood associated with RTD was significantly correlated with change of $\mathrm{rCBF}$ in the subgenual prefrontal cortex (PFC), and in the inferolateral region of the right posterior temporal cortex (Figure 1). In the contralateral (left) posterior temporal cortex, this association reached trend significance $(p=0.075)$. In these regions, the change in $\triangle$ VAMS score and change in $\mathrm{rCBF}$ covaried positively, so that as mood became less happy (ie increasingly positive $\triangle$ VAMS score) rCBF increased, and as mood became more happy rCBF decreased. The subgenual PFC cluster extended across the midline and included voxels in the left subgenual ACC (BA 25), left and right medial frontal gyri (BA 25) and extended into the right ventral striatum, left caudate nucleus, and right posteromedial orbitofrontal cortex (OFC; inferior frontal gyrus BA 11 and 47). The cluster in the right posterior temporal lobe included voxels in the inferior and middle temporal gyri (BA 20 and 37) and the cerebellum. There were no regions in which change in $\triangle$ VAMS and change in rCBF covaried negatively. Post hoc analysis of the subgenual region bilaterally, using smallvolume correction (sphere of radius $15 \mathrm{~mm}$, centered on the midline coordinate $016-10$, BA 25), indicated that the covariation between changes in mood and $\mathrm{rCBF}$ was also significant at the voxel level ( $p=0.037$, corrected for search volume of $14137 \mathrm{~mm}^{3}$ ).

When the variance in $\mathrm{rCBF}$ change associated with mood change was removed, the condition of RTD was associated with decreased $\mathrm{rCBF}$ in the left dorsal ACC (Figure 2), and with increased $\mathrm{rCBF}$ in a predominantly left sided inferoposterior cluster including the left cuneus (BA 17) in the occipital lobe, extending laterally into the left lingual gyrus (BA 18) and inferiorly into the superior aspect of the cerebellum bilaterally (Figure 3). Post hoc analysis of the dorsal ACC bilaterally, using small-volume correction (sphere of radius $15 \mathrm{~mm}$, centered on the midline coordinate 026 26), indicated that the reduction in $\mathrm{rCBF}$ associated with RTD was also significant at the voxel level $\left(p=0.020\right.$, corrected for search volume of $\left.14137 \mathrm{~mm}^{3}\right)$.

In all the above analyses, the identification of significant clusters was not altered when the data from the smoker or the subject on analgesic medication were removed (data not shown). 
Table I Regions with Significantly Altered rCBF Associated with Rapid Tryptophan Depletion

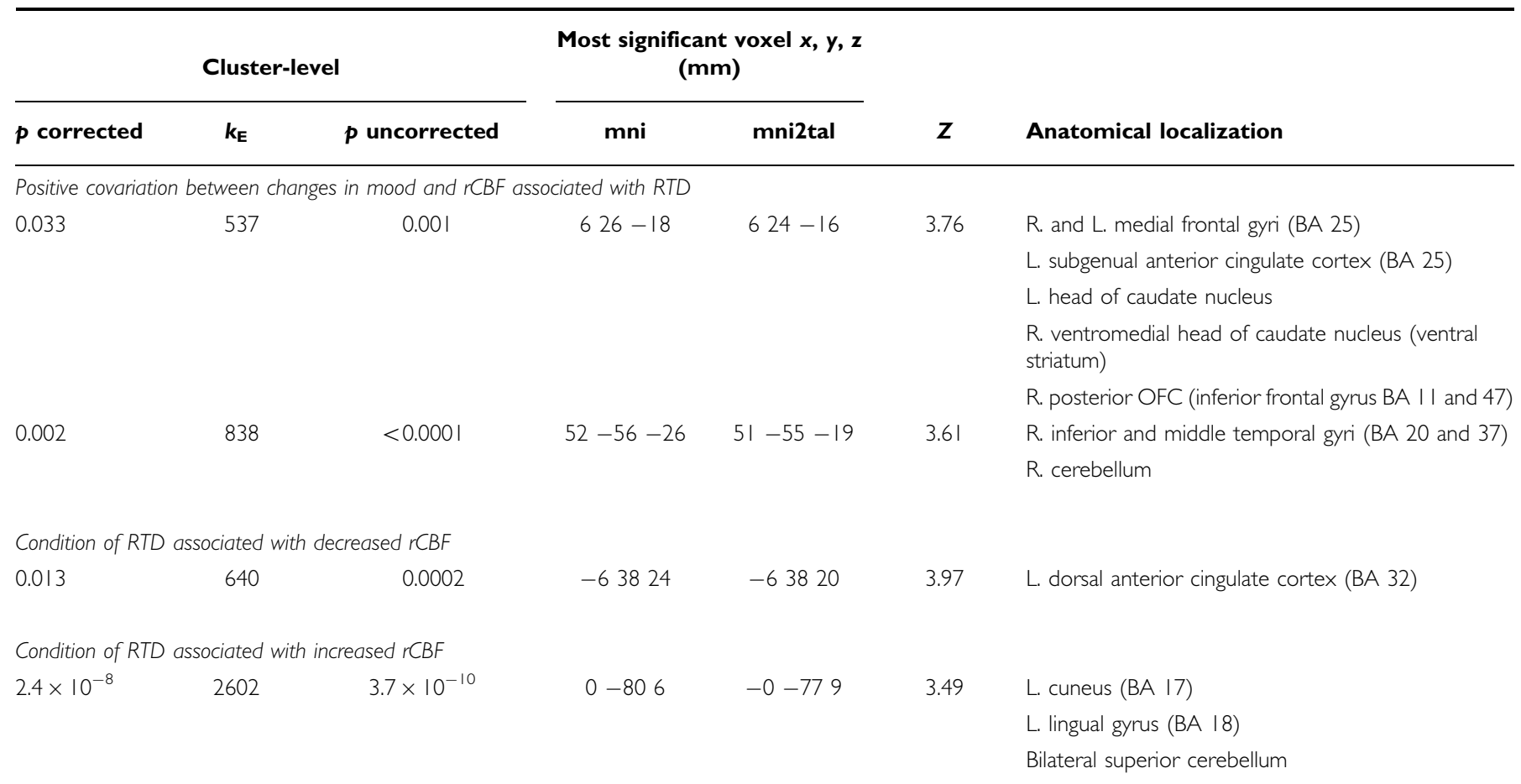

Significance assessed by cluster-level analysis (SPM99), $p \leqslant 0.05$ corrected for multiple comparisons across the whole brain; $k_{\mathrm{E}}$ : cluster extent (voxels); mni: coordinates in MNI brain space; coordinates following nonlinear transformation to the space of Talairach and Tournoux; BA: Brodmann's area.

A further post hoc analysis was performed to assess the relationship between rCBF changes in the subgenual PFC and dorsal ACC in individuals. For all SPECT scans, the activity value was extracted at the most significant voxel in the subgenual PFC cluster (6 $26-18$; BA 25) and the most significant voxel in the dorsal ACC cluster ( -638 24; BA 32) identified in the two primary analyses above. For each subject, the percent difference was calculated between the control and RTD conditions at both voxels. There was a tendency toward a negative relationship between RTDassociated rCBF changes in the two voxels, so that as rCBF increased in the subgenual PFC, rCBF decreased in the dorsal ACC, and vice versa (slope of linear regression $=-0.24)$. However, the correlation was far from statistically significant $\left(r^{2}=0.093 ; p=0.24\right)$.

\section{DISCUSSION}

This study has two main findings. First, in this group of healthy male subjects, the modest positive and negative changes in subjective happiness associated with RTD were significantly correlated with change of $\mathrm{rCBF}$ in the subgenual PFC, and in the inferolateral region of the right posterior temporal cortex. In these regions, as mood became less happy $\mathrm{rCBF}$ increased, and vice versa. The subgenual PFC cluster included the left subgenual ACC (BA 25), left and right medial frontal gyri (BA 25), right ventral striatum, left caudate nucleus, and right posterior OFC (inferior frontal gyrus BA 11 and 47). Second, independent of subjective mood change, RTD was associated with decreased $\mathrm{rCBF}$ in the left dorsal ACC, and increased occipital and superior cerebellar rCBF. These findings fit well with a large literature suggesting that the neurobiological basis of the different processes underlying normal emotion perception and its dysregulation in psychiatric disorders may be dependent upon the functioning of two neural systems (Phillips et al, 2003a,b). A ventral system, including the amygdala, insula, ventral striatum, and ventral regions of the ACC and PFC, is important for the identification of the emotional significance of stimuli and the production of affective states. A dorsal system, including hippocampus and the dorsal regions of the ACC and PFC, is important for the integration of emotional inputs and the performance of executive functions.

In relation to the ventral system, increased neuronal activity has been found in healthy subjects in the subgenual PFC (BA 25) during experimentally induced sadness (Damasio et al, 2000; George et al, 1995; Liotti et al, 2000, 2002; Mayberg et al, 1999), experimentally induced happiness (Damasio et al, 2000), happy memory retrieval (Markowitsch et al, 2003), and when evaluating emotional (both pleasant and unpleasant) target words (Elliott et al, 2000b; Maddock et al, 2003), whereas decreased activity in this region is associated with monetary reward (Pochon et al, 2002). Similar associations have been found in adjacent ventral ACC (ventral BA 24 and 32), where increased activity has been found during experimentally induced happiness (George et al, 1995; Lane et al, 1997) and sadness (Liotti et al, 2000), when identifying happy target words (Elliott et al, 2000b), and during a 'winning streak' on a simple gambling task (Elliott et al, 2000a). To the best of our knowledge, the current study is the first demonstration of this association following a neurochemical manipulation 

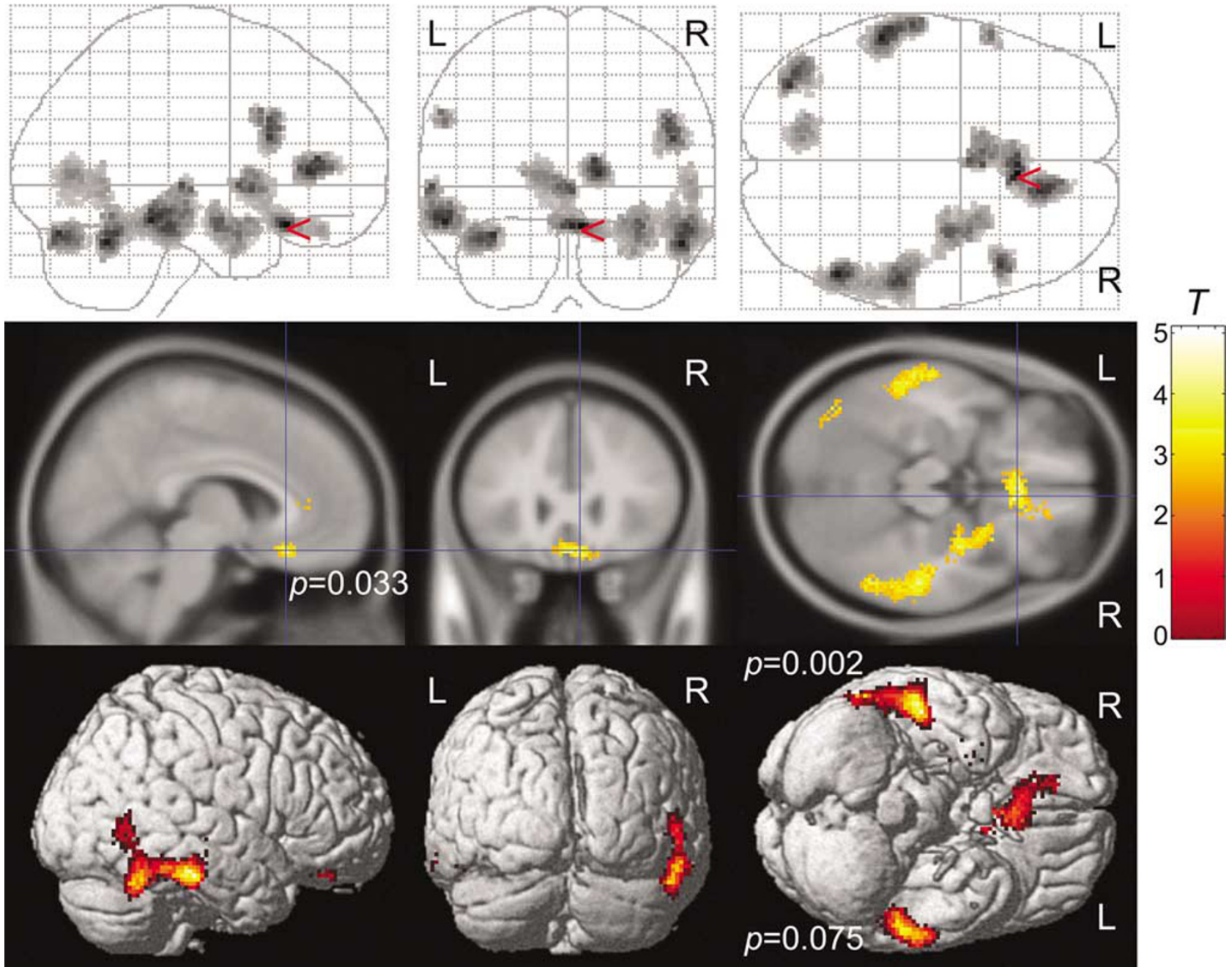

Figure I Regions (predominantly ventral) in which changes in subjective mood and rCBF associated with Trp depletion were correlated such that increasing sadness was associated with increased rCBF and vice versa. SPM99 T-maps (top row) are projected onto the high-resolution I52-subject average $\mathrm{T}_{1}$-weighted MRI image (middle row) and surface rendered (bottom row). Two significant clusters ( $p \leqslant 0.05$, corrected) were found: (i) in subgenual PFC (middle row; $p=0.033$, corrected) including left subgenual anterior cingulate cortex (BA 25), left and right medial frontal gyri (BA 25), right ventral striatum, left caudate nucleus, and right posteromedial OFC (inferior frontal gyrus BA II and 47); (ii) the inferolateral region of the right posterior temporal cortex (bottom row; $p=0.002$, corrected) including inferior and middle temporal gyri (BA 20 and 37) and the cerebellum. A cluster in the contralateral (left) posterior temporal cortex reached trend significance (bottom row; $p=0.075$, corrected). The arrow (top row) and cross-hair (middle row) are set at the most significant voxel in the brain volume.

in healthy humans. The relatively small magnitude of subjective mood changes, and the fact that the direction of the mood-rCBF covariation is the same as that found by a range of experimental methods, supports the idea that RTD is not inducing a pathological state in healthy humans. However, our results also demonstrate the association by reverse means, that is, by first altering function (by RTD), whereas the association has previously been demonstrated by paradigms that first manipulate mood.

In contrast, a significant mood deterioration and directionally opposite rCBF changes in subgenual ACC have been found following RTD in (mostly medicated) patients with MDD, despite a comparable reduction in plasma Trp to that induced in our healthy subjects (Smith et al, 1999). This strongly suggests that the pathological mood and brain activity seen in patients with MDD following reduced 5-HT are mediated by dysfunctional postsynaptic mechanisms that represent a trait vulnerability. This is supported by recent PET neuroreceptor imaging findings following RTD (Praschak-Rieder et al, 2004), and an increasing literature demonstrating structural and/or functional abnormalities in subgenual PFC in MDD (see eg, Drevets, 2000b; Harrison, 2002; Mayberg et al, 2005; Ongur et al, 1998; Pizzagalli et al, 2004). An alternative explanation would be that the pathological effects of RTD in patients with MDD are due to a potentiated reduction in extracellular 5-HT secondary to serotonergic medication, as seen in animal studies (Bel and Artigas, 1996). Interestingly, increasing depression scores were not correlated with change of rCMRglc in subgenual PFC in unmedicated patients with MDD (Neumeister et al, 2004). However, the RTD-induced depressive symptoms in that study were mild, and ${ }^{18} \mathrm{~F}$-FDG may not be an ideal tracer to investigate correlations with relatively transient mood states due to the 

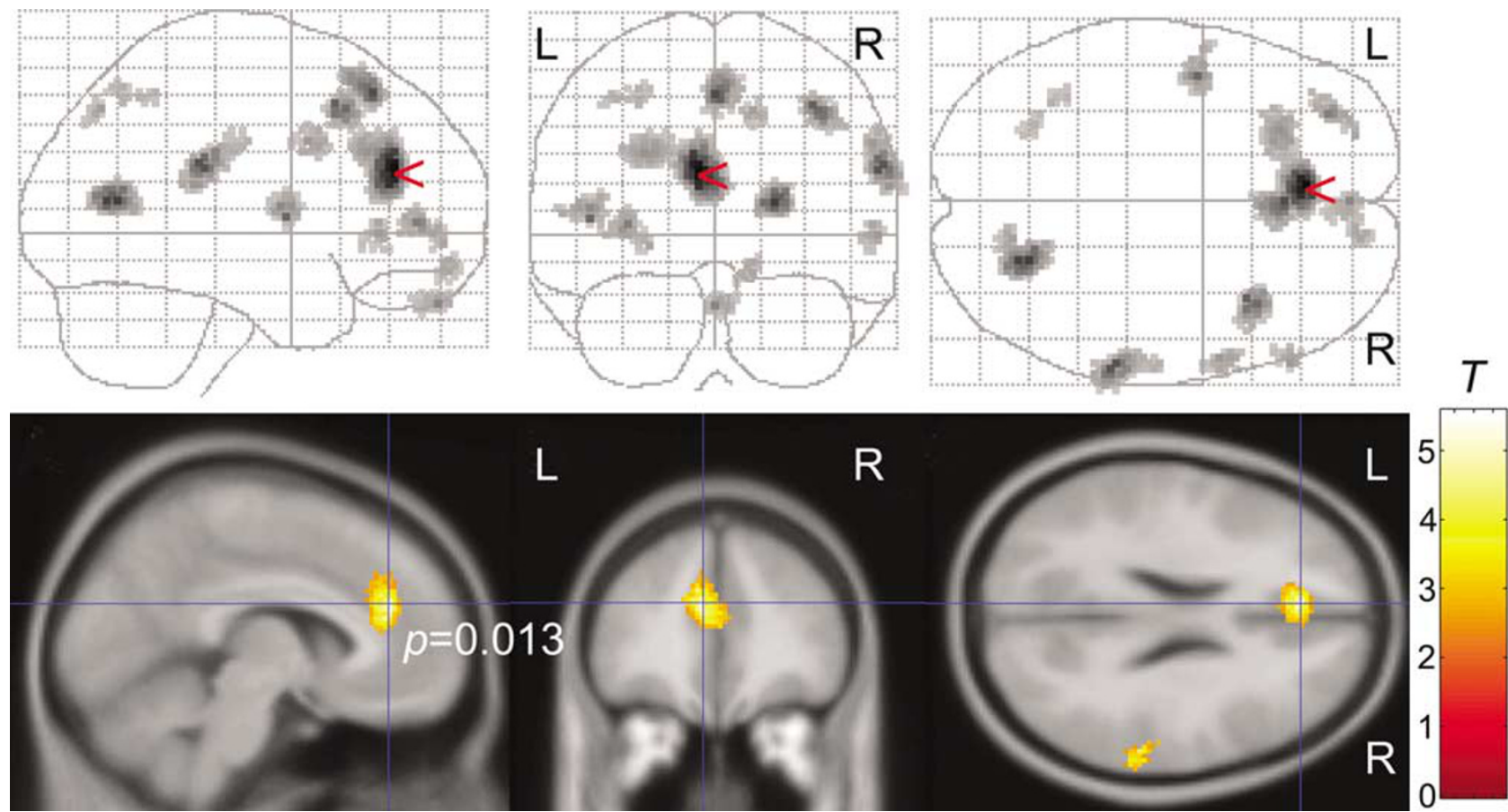

Figure 2 Regions (predominantly dorsal) in which RTD is associated with decreased rCBF, independent of subjective mood change. SPM99 T-maps (top row) are projected onto the high-resolution I52-subject average $T_{1}$-weighted MRI image (bottom row). One significant cluster ( $p=0.013$ ) was found, in dorsal anterior cingulate cortex (BA 32). The arrow (top row) and cross-hair (bottom row) are set at the most significant voxel in the brain volume.
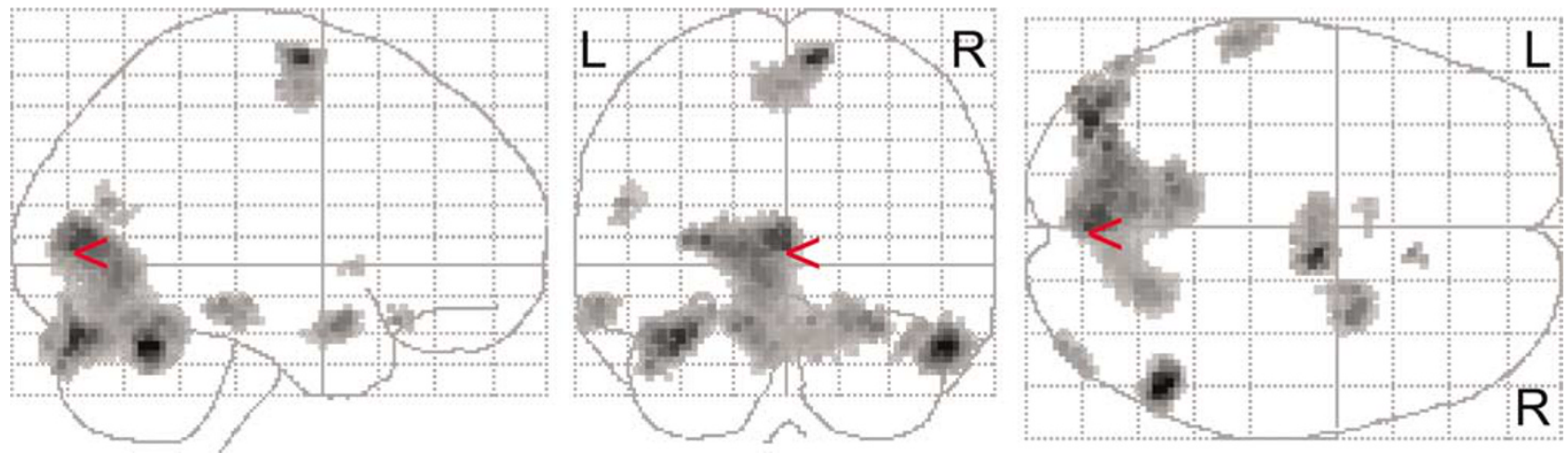

Figure 3 SPM99 T-maps showing regions in which RTD is associated with increased rCBF, independent of subjective mood change. One cluster was significant ( $p=2.4 \times 10^{-8}$, corrected): a posterior, predominantly left sided, cluster including the left cuneus (BA 17) in the occipital lobe, extending laterally into the left lingual gyrus (BA 18) and inferiorly into the superior aspect of the cerebellum bilaterally.

difficulty in standardizing subjects' mental state during its protracted uptake. Moreover, such an explanation is strongly undermined by an absence of RTD-induced mood deterioration in healthy subjects on SSRI medication (Barr et al, 1997), and of a different subgenual PFC rCBF response in patients with MDD (compared to healthy controls) to nonpharmacologically induced sadness (Liotti et al, 2002). Imaging studies of the neural correlates of RTD in SSRItreated healthy subjects and in unmedicated patients with MDD using modalities with higher temporal resolution (functional magnetic resonance imaging studies (fMRI), ${ }^{15}$ O-labeled water PET, ${ }^{99 \mathrm{~m}}$ Tc-HMPAO SPECT) will be instructive.

With regard to the finding that RTD is associated with reduced $\mathrm{rCBF}$ in the left dorsal ACC independent of mood change, functional neuroimaging research has established that the ACC is functionally divided into relatively distinct cognitive (dorsal) and affective (ventral) areas (Allman et al, 2001; Bush et al, 2000; Devinsky et al, 1995; Paus, 2001; Vogt et al, 1992). The dorsal ACC is activated by a wide range of higher cognitive functions, including tasks in which a prepotent or over-learned response tendency has to be overcome (such as the Stroop and the Go/No-go task), when the response to be made is not fully constrained by the task context (including verb generation, verbal fluency, and stem completion) and tasks that typically either elicit, or result from, response conflict. In addition, the dorsal ACC plays a role in anticipating and detecting targets, indicating novelty, influencing motor responses, and encoding reward values. If the reduced $\mathrm{rCBF}$ in dorsal ACC following RTD in the 
present study is associated with altered regional function, this may suggest that at least some of the alterations in cognition consistently noted in healthy subjects following RTD may be attributable to altered function in the dorsal ACC, particularly cognitive tasks known to recruit the dorsal ACC such as Stroop performance and decisionmaking cognition. An obvious limitation is that cognitive function was not measured during this SPECT study, precluding the direct demonstration of an association between altered dorsal ACC rCBF and task performance following RTD. However, our finding does provide a hypothesis that can be tested using the more sophisticated designs and technologies available with ${ }^{15} \mathrm{O}$-labeled water PET or fMRI.

The mood-associated and mood-independent $\mathrm{rCBF}$ changes following RTD seen in more posterior brain regions in the present study support the dissociation seen in affective and cognitive subdivisions of the ACC. Previous studies have also reported altered activity in the cerebellum and posterior inferior temporal cortex bilaterally with grief or sad mood provocation in healthy and depressed subjects (Gundel et al, 2003; Liotti et al, 2002), suggesting that these regions form part of the ventral neural system mentioned above. The increases seen in occipital and superior cerebellar rCBF independent of mood change may suggest that the posterior (visuospatial) attentional system may also be affected by RTD. In this regard, it may be significant that there was a visuospatial component (completing paper mood rating scales) to the mental state of the subjects at the time of radiotracer injection, although no formal test of visuospatial performance was performed.

The changes in $\mathrm{rCBF}$ and rCMRglc associated with functional activation as measured by fMRI and PET/SPECT predominantly represent the glutamatergic and GABAergic metabolic demands of presynaptic terminals (Jueptner and Weiller, 1995; Shulman, 2001). Although less is known about incremental activity changes induced by pharmacological interventions, it seems unlikely that following RTD we are observing changes in $\mathrm{rCBF}$ directly related to metabolic changes in serotonergic terminals, as these are unlikely to be measurable against the high level of background glutamatergic metabolic requirements. Rather, the SPM T-maps most likely indicate areas in which glutamate and GABA neurotransmission are modulated by reduced 5-HT, either directly or indirectly through effects on other neurotransmitter systems, particularly dopamine (DA). A direct effect is supported by studies of rat cingulate cortex demonstrating that 5-HT presynaptically inhibits the release of Glu at synapses onto prefrontal pyramidal neurons and local GABAergic inhibitory interneurons (Tanaka and North, 1993). An indirect effect of 5-HT may be suggested by the high levels of other neurotransmitters and modulators found in the ACC (Paus, 2001). For example, the density of DA fibers in the dorsal ACC is among the highest in human cortex. Serotonergic modulation of DA has been demonstrated in vivo in humans (Smith et al, 1997), and dopaminergic manipulations are known to alter activity in human ACC (Bartlett et al, 1994; Grasby et al, 1993; Kapur et al, 1994; Paus, 2001), whereas impaired subcortical DA function is correlated with impaired performance on the Stroop Color Word interference task (Bruck et al, 2001; Rinne et al, 2000; Volkow et al, 1998), a task which activates the dorsal ACC and has altered performance following RTD.

The differential effects of reduced 5-HT on $\mathrm{rCBF}$ in the dorsal ACC and subgenual PFC would be consistent with the fact that the heterogeneity in the cyto- and chemoarchitecture of the human ACC includes significant differences between dorsal and ventral subregions (Gittins and Harrison, 2004; Nimchinsky et al, 1997). For example, in humans, the densities of serotonergic innervation, 5-HT transporters (SERT) and 5- $\mathrm{HT}_{1 \mathrm{~A}}$ receptors are higher in subgenual than dorsal ACC, whereas $5-\mathrm{HT}_{4}$ receptor density is lower, and $5-\mathrm{HT}_{2 \mathrm{~A}}$ and $5-\mathrm{HT}_{1 \mathrm{~B}}$ receptors are more evenly distributed (Varnas et al, 2004). Moreover, structure, function, and interconnections within the ventral neural system (including the peri- and subgenual ACC and amygdala) are affected by functional variation in the SERT gene (Pezawas et al, 2005). In the human DA system, there is a ventrodorsal gradient in $D_{1}$ receptor density such that the medial orbitofrontal (BA 11,14) and subgenual (BA 25, 32) regions contain the highest expression of $D_{1}$ receptor mRNA found outside the striatum, whereas (dorsal) ACC levels are lower. Like other cortical areas, $\mathrm{D}_{2}$ receptor density in these regions is extremely low (an order of magnitude lower than $D_{1}$ receptors), but would appear to be even lower (essentially negligible) subgenually than in dorsal ACC (Hall et al, 1996; Hurd et al, 2001). In nonhuman primates, there is evidence that $\mathrm{D}_{3}$ receptor activation preferentially affects neural activity in OFC and subgenual ACC in comparison to dorsal ACC, which has been suggested may provide a functional basis for studies linking anxiety and depression with DA and subgenual ACC (Black et al, 2002). In addition to the cytoarchitectural and anatomical distinctions delineating these areas, there is now evidence in rodents for a double dissociation between the functions of the DA and 5-HT systems within the medial PFC and OFC regions in the mediation of behavior (Winstanley et al, 2005). These observations may provide a reasonable basis on which future studies may hypothesize that the differential effects of RTD on neural activity, mood, and cognition in humans may be mediated via a double dissociation between serotonergic and nonserotonergic (including dopaminergic) mechanisms in the ventral and dorsal neural systems.

Finally, we do not claim that the findings reported here are the only neural correlates of RTD. It is likely that only rCBF changes of relatively large spatial extent can be detected in a SPECT study of this nature. The resolution limit of the camera already limits the detection of $\mathrm{rCBF}$ changes of small spatial extent and magnitude, and other practical factors further deteriorate the sensitivity for detection of $\mathrm{rCBF}$ change, including lack of scatter correction, motion artefacts, intersubject coregistration, and spatial normalization. Moreover, the sensitivity for detecting even relatively large $\mathrm{rCBF}$ changes will vary across different brain regions. Studies using more sensitive imaging modalities may identify more subtle neural correlates of RTD undetectable in the current study. On the other hand, the above factors do not invalidate the positive findings of the study. When appropriate correction for multiple comparisons is made, false-positive clusters would appear to be extremely well controlled for in voxelbased statistical analysis of SPECT neuroactivation studies 
with SPM (Van Laere et al, 2002). In addition, the rCBF changes associated with RTD may possibly vary with the magnitude of the depletion of brain Trp (and subsequent 5 -HT) achieved in a given study. As the measured effect of RTD is determined by the difference between the effects of the Trp-free ( $\mathrm{T}-$ ) and control $(\mathrm{T}+)$ drinks, it may be diminished if the $\mathrm{T}+$ drink does not have a truly neutral effect on brain 5-HT. In fact, there is increasing evidence that the Trp content of the $\mathrm{T}+$ mixture in many typical RTD studies (including this one) is not high enough to prevent a modest reduction in brain Trp in the control condition. This is because brain entry of Trp is controlled principally by the ratio of plasma Trp to the other large neutral amino acids (Trp/ $/$ LNAA ratio) that compete with Trp for the same transport mechanism across the bloodbrain barrier. Studies using $\mathrm{T}+$ mixtures with a similar Trp content to the current study $(\sim 2.3 \%)$ have shown that the increase in other plasma LNAAs is proportionately greater than the increase in plasma Trp, resulting in a modest reduction in the Trp/ $\Sigma$ LNAA ratio and (presumably) reduced brain entry of Trp (Talbot et al, 2005; Wolfe et al, 1995). Although we did not measure the Trp/LNAA ratio, it is reasonable to suppose that the effects of the $\mathrm{T}$ - condition (robust central Trp depletion) on $\mathrm{rCBF}$ in the current study may have been somewhat attenuated by the contrast with a non-neutral $\mathrm{T}+$ condition (modest central Trp depletion). Although the intent of this study was to investigate the neural correlates of a typical RTD paradigm, future studies may wish to investigate whether the use of a $\mathrm{T}+$ mixture with a more neutral effect on brain 5-HT may increase the sensitivity for detecting the neural and mood correlates of RTD.

In conclusion, our findings would suggest that the dissociation seen between affective and cognitive consequences of RTD in healthy humans may possibly be attributable to differential effects of reduced 5-HT, acting either directly or indirectly via other neurotransmitter systems, on ventral and dorsal neural systems that regulate and integrate affective and cognitive functions.

\section{ACKNOWLEDGEMENTS}

We thank Adrian Devine for performing the serum tryptophan assays; Klaus Ebmeier, Brian Gilmore, Mike Glabus, Peter Jarritt, and Jim Patterson for practical advice related to the initiation of brain SPECT in Belfast; Stephen Vallely and Lynn Elliott in the Belfast City Hospital for assistance with the gamma camera; Anna Barnes, Mark Slifstein, and Eric Zarahn for helpful advice and discussions related to SPM. We acknowledge the financial assistance of the Research \& Development office of the Northern Ireland Health and Personal Social Services, and Ulster Garden Villages, Ltd.

\section{REFERENCES}

Allman JM, Hakeem A, Erwin JM, Nimchinsky E, Hof P (2001). The anterior cingulate cortex. The evolution of an interface between emotion and cognition. Ann N Y Acad Sci 935: 107-117.

Ashburner J, Friston KJ (1999). Nonlinear spatial normalization using basis functions. Hum Brain Mapp 7: 254-266.
Ashburner J, Neelin P, Collins DL, Evans A, Friston K (1997). Incorporating prior knowledge into image registration. Neuroimage 6: 344-352.

Barr LC, Heninger GR, Goodman W, Charney DS, Price LH (1997). Effects of fluoxetine administration on mood response to tryptophan depletion in healthy subjects. Biol Psychiatry 41: 949-954.

Bartlett EJ, Brodie JD, Simkowitz P, Dewey SL, Rusinek H, Wolf AP et al (1994). Effects of haloperidol challenge on regional cerebral glucose utilization in normal human subjects. Am J Psychiatry 151: 681-686.

Beck A, Ward C, Mendelson M, Mock J, Erbaugh J (1961). An inventory for measuring depression. Arch Gen Psychiatry 4: 561-571.

Bel N, Artigas F (1996). Reduction of serotonergic function in rat brain by tryptophan depletion: effects in control and fluvoxamine-treated rats. J Neurochem 67: 669-676.

Black KJ, Hershey T, Koller JM, Videen TO, Mintun MA, Price JL et al (2002). A possible substrate for dopamine-related changes in mood and behavior: prefrontal and limbic effects of a D3-preferring dopamine agonist. Proc Natl Acad Sci USA 99: 17113-17118.

Booij L, Van der Does AJ, Riedel WJ (2003). Monoamine depletion in psychiatric and healthy populations: review. Mol Psychiatry 8: 951-973.

Bremner JD, Innis RB, Salomon RM, Staib LH, Ng CK, Miller HL et al (1997). Positron emission tomography measurement of cerebral metabolic correlates of tryptophan depletion-induced depressive relapse. Arch Gen Psychiatry 54: 364-374.

Bruck A, Portin R, Lindell A, Laihinen A, Bergman J, Haaparanta $\mathrm{M}$ et al (2001). Positron emission tomography shows that impaired frontal lobe functioning in Parkinson's disease is related to dopaminergic hypofunction in the caudate nucleus. Neurosci Lett 311: 81-84.

Bush G, Luu P, Posner MI (2000). Cognitive and emotional influences in anterior cingulate cortex. Trends Cogn Sci 4: 215-222.

Coull JT, Sahakian BJ, Middleton HC, Young AH, Park SB, McShane RH et al (1995). Differential effects of clonidine, haloperidol, diazepam and tryptophan depletion on focused attention and attentional search. Psychopharmacology (Berlin) 121: 222-230.

Damasio AR, Grabowski TJ, Bechara A, Damasio H, Ponto LL, Parvizi J et al (2000). Subcortical and cortical brain activity during the feeling of self-generated emotions. Nat Neurosci 3: 1049-1056.

Devinsky O, Morrell MJ, Vogt BA (1995). Contributions of the anterior cingulate gyrus to behavior. Brain 118: 279-306.

Drevets WC (2000a). Functional anatomical abnormalities in limbic and prefrontal cortical structures in major depression. Prog Brain Res 126: 413-431.

Drevets WC (2000b). Neuroimaging studies of mood disorders. Biol Psychiatry 48: 813-829.

Ebmeier KP, Dougall NJ, Austin M-P (1991). The split-dose technique for the study of psychological and pharmacological activation with the cerebral blood flow marker exametazime and single photon emission computed tomography (SPECT): reproducibility and rater reliability. Int J Methods Psychiatr Res 1: 27-38.

Elliott R, Friston KJ, Dolan RJ (2000a). Dissociable neural responses in human reward systems. J Neurosci 20: 61596165.

Elliott R, Rubinsztein JS, Sahakian BJ, Dolan RJ (2000b). Selective attention to emotional stimuli in a verbal go/no-go task: an fMRI study. Neuroreport 11: 1739-1744.

Folstein MF, Luria R (1973). Reliability, validity, and clinical application of the visual analogue mood scale. Psychol Med 3: 479-486. 
Frackowiak RSJ, Friston KJ, Frith CD, Dolan RJ, Mazziotta JC (1997). Human Brain Function. Academic Press: San Diego, USA.

George MS, Ketter TA, Parekh PI, Horwitz B, Herscovitch P, Post RM (1995). Brain activity during transient sadness and happiness in healthy women. Am J Psychiatry 152: 341-351.

Gittins R, Harrison PJ (2004). A quantitative morphometric study of the human anterior cingulate cortex. Brain Res 1013: 212-222.

Grasby PM, Friston KJ, Bench CJ, Cowen PJ, Frith CD, Liddle PF et al (1993). The effect of the dopamine agonist, apomorphine, on regional cerebral blood flow in normal volunteers. Psychol Med 23: 605-612.

Gundel H, O'Connor MF, Littrell L, Fort C, Lane RD (2003). Functional neuroanatomy of grief: an FMRI study. $A m \mathrm{~J}$ Psychiatry 160: 1946-1953.

Hall H, Farde L, Halldin C, Hurd YL, Pauli S, Sedvall GC (1996). Autoradiographic localization of extrastriatal D2-dopamine receptors in the human brain using [125I]epidepride. Synapse 23: $115-123$.

Harrison BJ, Olver JS, Norman TR, Burrows GD, Wesnes KA, Nathan PJ (2004). Selective effects of acute serotonin and catecholamine depletion on memory in healthy women. $J$ Psychopharmacol (Oxford) 18: 32-40.

Harrison PJ (2002). The neuropathology of primary mood disorder. Brain 125: 1428-1449.

Hurd YL, Suzuki M, Sedvall GC (2001). D1 and D2 dopamine receptor mRNA expression in whole hemisphere sections of the human brain. J Chem Neuroanat 22: 127-137.

Jueptner M, Weiller C (1995). Does measurement of regional cerebral blood flow reflect synaptic activity? Implications for PET and fMRI. Neuroimage 2: 148-156.

Kapur S, Meyer J, Wilson AA, Houle S, Brown GM (1994). Activation of specific cortical regions by apomorphine: an [15O $] \mathrm{H}_{2} \mathrm{O}$ PET study in humans. Neurosci Lett 176: 21-24.

Klaassen T, Riedel WJ, Deutz NE, Van Praag HM (2002). Mood congruent memory bias induced by tryptophan depletion. Psychol Med 32: 167-172.

Klaassen T, Riedel WJ, Deutz NE, van Someren A, van Praag HM (1999). Specificity of the tryptophan depletion method. Psychopharmacology (Berlin) 141: 279-286.

Lane RD, Reiman EM, Ahern GL, Schwartz GE, Davidson RJ (1997). Neuroanatomical correlates of happiness, sadness, and disgust. Am J Psychiatry 154: 926-933.

Liotti M, Mayberg HS (2001). The role of functional neuroimaging in the neuropsychology of depression. J Clin Exp Neuropsychol 23: $121-136$

Liotti M, Mayberg HS, Brannan SK, McGinnis S, Jerabek P, Fox PT (2000). Differential limbic - cortical correlates of sadness and anxiety in healthy subjects: implications for affective disorders. Biol Psychiatry 48: 30-42.

Liotti M, Mayberg HS, McGinnis S, Brannan SL, Jerabek P (2002). Unmasking disease-specific cerebral blood flow abnormalities: mood challenge in patients with remitted unipolar depression. Am J Psychiatry 159: 1830-1840.

Maddock RJ, Garrett AS, Buonocore MH (2003). Posterior cingulate cortex activation by emotional words: fMRI evidence from a valence decision task. Hum Brain Mapp 18: 30-41.

Markowitsch HJ, Vandekerckhovel MM, Lanfermann H, Russ MO (2003). Engagement of lateral and medial prefrontal areas in the ecphory of sad and happy autobiographical memories. Cortex 39: 643-665.

Mayberg HS, Liotti M, Brannan SK, McGinnis S, Mahurin RK, Jerabek PA et al (1999). Reciprocal limbic-cortical function and negative mood: converging PET findings in depression and normal sadness. Am J Psychiatry 156: 675-682.

Mayberg HS, Lozano AM, Voon V, McNeely HE, Seminowicz D, Hamani C et al (2005). Deep brain stimulation for treatmentresistant depression. Neuron 45: 651-660.
McAllister-Williams RH, Massey AE, Rugg MD (2002). Effects of tryptophan depletion on brain potential correlates of episodic memory retrieval. Psychopharmacology (Berlin) 160: 434-442.

Moore P, Landolt HP, Seifritz E, Clark C, Bhatti T, Kelsoe J et al (2000). Clinical and physiological consequences of rapid tryptophan depletion. Neuropsychopharmacology 23: 601-622.

Morris JS, Smith KA, Cowen PJ, Friston KJ, Dolan RJ (1999). Covariation of activity in habenula and dorsal raphe nuclei following tryptophan depletion. Neuroimage 10: 163-172.

Neumeister A, Nugent AC, Waldeck T, Geraci M, Schwarz M, Bonne $\mathrm{O}$ et al (2004). Neural and behavioral responses to tryptophan depletion in unmedicated patients with remitted major depressive disorder and controls. Arch Gen Psychiatry 61: 765-773.

Nimchinsky EA, Vogt BA, Morrison JH, Hof PR (1997). Neurofilament and calcium-binding proteins in the human cingulate cortex. J Comp Neurol 384: 597-620.

Ongur D, Drevets WC, Price JL (1998). Glial reduction in the subgenual prefrontal cortex in mood disorders. Proc Natl Acad Sci USA 95: 13290-13295.

Park SB, Coull JT, McShane RH, Young AH, Sahakian BJ, Robbins TW et al (1994). Tryptophan depletion in normal volunteers produces selective impairments in learning and memory. Neuropharmacology 33: 575-588.

Paus T (2001). Primate anterior cingulate cortex: where motor control, drive and cognition interface. Nat Rev Neurosci 2: 417-424.

Pergadia M, Spring B, Konopka LM, Twardowska B, Shirazi P, Crayton JW (2004). Double-blind trial of the effects of tryptophan depletion on depression and cerebral blood flow in smokers. Addict Behav 29: 665-671.

Pezawas L, Meyer-Lindenberg A, Drabant EM, Verchinski BA, Munoz KE, Kolachana BS et al (2005). 5-HTTLPR polymorphism impacts human cingulate-amygdala interactions: a genetic susceptibility mechanism for depression. Nat Neurosci 8: 828-834.

Phillips ML, Drevets WC, Rauch SL, Lane R (2003a). Neurobiology of emotion perception I: The neural basis of normal emotion perception. Biol Psychiatry 54: 504-514.

Phillips ML, Drevets WC, Rauch SL, Lane R (2003b). Neurobiology of emotion perception II: Implications for major psychiatric disorders. Biol Psychiatry 54: 515-528.

Pizzagalli DA, Oakes TR, Fox AS, Chung MK, Larson CL, Abercrombie HC et al (2004). Functional but not structural subgenual prefrontal cortex abnormalities in melancholia. Mol Psychiatry 9: 393-405.

Pochon JB, Levy R, Fossati P, Lehericy S, Poline JB, Pillon B et al (2002). The neural system that bridges reward and cognition in humans: an fMRI study. Proc Natl Acad Sci USA 99: 5669-5674.

Praschak-Rieder N, Hussey D, Wilson AA, Carella A, Lee M, Dunn $\mathrm{E}$ et al (2004). Tryptophan depletion and serotonin loss in selective serotonin reuptake inhibitor-treated depression: an [(18)F] MPPF positron emission tomography study. Biol Psychiatry 56: 587-591.

Riedel WJ (2004). Cognitive changes after acute tryptophan depletion: what can they tell us? Psychol Med 34: 3-8.

Riedel WJ, Klaassen T, Deutz NE, van Someren A, van Praag HM (1999). Tryptophan depletion in normal volunteers produces selective impairment in memory consolidation. Psychopharmacology (Berlin) 141: 362-369.

Rinne JO, Portin R, Ruottinen H, Nurmi E, Bergman J, Haaparanta $M$ et al (2000). Cognitive impairment and the brain dopaminergic system in Parkinson disease: [18F]fluorodopa positron emission tomographic study. Arch Neurol 57: 470-475.

Rogers RD, Blackshaw AJ, Middleton HC, Matthews K, Hawtin K, Crowley C et al (1999a). Tryptophan depletion impairs stimulus-reward learning while methylphenidate disrupts attentional control in healthy young adults: implications for 
the monoaminergic basis of impulsive behaviour. Psychopharmacology (Berlin) 146: 482-491.

Rogers RD, Everitt BJ, Baldacchino A, Blackshaw AJ, Swainson R, Wynne $\mathrm{K}$ et al (1999b). Dissociable deficits in the decisionmaking cognition of chronic amphetamine abusers, opiate abusers, patients with focal damage to prefrontal cortex, and tryptophan-depleted normal volunteers: evidence for monoaminergic mechanisms. Neuropsychopharmacology 20: 322-339.

Rogers RD, Tunbridge EM, Bhagwagar Z, Drevets WC, Sahakian BJ, Carter CS (2003). Tryptophan depletion alters the decisionmaking of healthy volunteers through altered processing of reward cues. Neuropsychopharmacology 28: 153-162.

Rowley B, Van F, Mortimore C, Connell J (1997). Effects of acute tryptophan depletion on tests of frontal and temporal lobe function. J Psychopharmacol (Oxford) 11: A60.

Rubinsztein JS, Rogers RD, Riedel WJ, Mehta MA, Robbins TW, Sahakian BJ (2001). Acute dietary tryptophan depletion impairs maintenance of 'affective set' and delayed visual recognition in healthy volunteers. Psychopharmacology (Berlin) 154: 319-326.

Schmitt JA, Jorissen BL, Sobczak S, van Boxtel MP, Hogervorst E, Deutz NE et al (2000). Tryptophan depletion impairs memory consolidation but improves focussed attention in healthy young volunteers. J Psychopharmacol (Oxford) 14: 21-29.

Seminowicz DA, Mayberg HS, McIntosh AR, Goldapple K, Kennedy S, Segal Z et al (2004). Limbic-frontal circuitry in major depression: a path modeling metanalysis. Neuroimage 22: 409-418.

Shulman RG (2001). Functional imaging studies: Linking mind and basic neuroscience. Am J Psychiatry 158: 11-20.

Smith GS, Dewey SL, Brodie JD, Logan J, Vitkun SA, Simkowitz P et al (1997). Serotonergic modulation of dopamine measured with [11C]raclopride and PET in normal human subjects. Am J Psychiatry 154: 490-496.

Smith KA, Morris JS, Friston KJ, Cowen PJ, Dolan RJ (1999). Brain mechanisms associated with depressive relapse and associated cognitive impairment following acute tryptophan depletion. $\mathrm{Br} \mathrm{J}$ Psychiatry 174: 525-529.

Sobczak S, Riedel WJ, Booij I, Aan Het Rot M, Deutz NE, Honig A (2002). Cognition following acute tryptophan depletion: differ- ence between first-degree relatives of bipolar disorder patients and matched healthy control volunteers. Psychol Med 32: 503-515.

Spielberger CD, Gorsuch RL, Lushene RG (1971). Manual for the State-Trait Anxiety Inventory. Consulting Press: Palo Alto, CA.

Talairach J, Tournoux P (1988). Co-Planar Stereotaxic Atlas of the Human Brain. Thieme Medical Publishers, Inc: New York.

Talbot PS, Frankle WG, Hwang D-R, Huang Y, Suckow RF, Slifstein $M$ et al (2005). Effects of reduced endogenous 5-HT on the in vivo binding of the serotonin transporter radioligand 11C-DASB in healthy humans. Synapse 55: 164-175.

Tanaka E, North RA (1993). Actions of 5-hydroxytryptamine on neurons of the rat cingulate cortex. J Neurophysiol 69: 1749-1757.

Van Laere KJ, Versijpt J, Koole M, Vandenberghe S, Lahorte P, Lemahieu I et al (2002). Experimental performance assessment of SPM for SPECT neuroactivation studies using a subresolution sandwich phantom design. Neuroimage 16: 200-216.

Varnas K, Halldin C, Hall H (2004). Autoradiographic distribution of serotonin transporters and receptor subtypes in human brain. Hum Brain Mapp 22: 246-260.

Vogt BA, Finch DM, Olson CR (1992). Functional heterogeneity in cingulate cortex: the anterior executive and posterior evaluative regions. Cereb Cortex 2: 435-443.

Volkow ND, Gur RC, Wang GJ, Fowler JS, Moberg PJ, Ding YS et al (1998). Association between decline in brain dopamine activity with age and cognitive and motor impairment in healthy individuals. Am J Psychiatry 155: 344-349.

Winstanley CA, Theobald DE, Dalley JW, Cardinal RN, Robbins TW (2005). Double dissociation between serotonergic and dopaminergic modulation of medial prefrontal and orbitofrontal cortex during a test of impulsive choice. Cereb Cortex Advance Access, published April 13, 2005, doi:101093/cercor/bhi088.

Wolfe BE, Metzger ED, Jimerson DC (1995). Comparison of the effects of amino acid mixture and placebo on plasma tryptophan to large neutral amino acid ratio. Life Sci 56: 1395-1400.

Worsley KJ, Marrett S, Neelin P, Vandal KJ, Evans AC (1996). A unified statistical approach for determining significant voxels in images of cerebral activation. Hum Brain Mapp 4: 58-73. 